CASE REPORT

\title{
Massive acute haemolysis in neonates with glucose-6- phosphate dehydrogenase deficiency
}

\author{
A S Dhillon, P J Darbyshire, M D Williams, J G Bissenden
}

Arch Dis Child Fetal Neonatal Ed 2003;88:F534-F536

Three neonates with glucose-6-phosphate dehydrogenase (G6PD) deficiency are described. All three patients suffered an episode of massive acute haemolysis, in the absence of blood group incompatibilities, infection, or ingestion of oxidising agents known to trigger haemolysis. One patient died, but the other two survived after an exchange transfusion. This highlights that G6PD deficiency in the neonatal period may present with severe anaemia in association with hyperbilirubinaemia.

G lucose-6-phosphate dehydrogenase (G6PD) deficiency is a genetic enzymatic disorder that affects hundreds of millions of people world wide. ${ }^{12}$ Severe hyperbilirubinaemia and kernicterus, the most health threatening consequences of this disorder in the newborn period, have been well documented in many population groups. ${ }^{23}$

Hyperbilirubinaemia in neonates with G6PD deficiency is thought to be secondary to reduced hepatic conjugation and excretion of bilirubin ${ }^{1245}$ rather than increased bilirubin production resulting from haemolysis. ${ }^{3}$ Anaemia is often not reported in G6PD deficient neonates who develop hyperbilirubinaemia or even kernicterus. Massive acute haemolysis is thought not to occur in the absence of trigger factors ${ }^{2}{ }^{6}$ in the newborn period.

We describe three neonates with G6PD deficiency who developed severe hyperbilirubinaemia requiring exchange transfusion because of massive acute haemolysis, in the absence of any obvious blood group incompatibilities, infection, or ingestion of oxidising agents known to trigger haemolysis by either the mother or infant.

\section{CASE REPORTS}

Cases 1 and 2 were monozygotic twins of non-consanguineous Indian parents with an unremarkable medical history. The pregnancy was uncomplicated until spontaneous onset of labour at 28 weeks gestation. Although the mother (blood group O positive) had taken chloroquine (Nivaquine; RhonePoulenc Rorer, West Malling, Kent, UK) as malaria prophylaxis in the first trimester, there was no other history of drug or fava bean ingestion.

Twin 1 was a $970 \mathrm{~g}$ boy of blood group O positive, direct Coombs test (DCT) negative, and haemoglobin $(\mathrm{Hb})$ concentration $139 \mathrm{~g} / \mathrm{l}$ at birth. He required intubation, ventilation, and exogenous surfactant for classical respiratory distress syndrome. Vitamin $\mathrm{K}_{1}$ (Konakion MM; Roche; $0.1 \mathrm{mg}$ ) was given intramuscularly. By day 3 his condition had improved sufficiently to be extubated and total parenteral nutrition (TPN) started. Jaundice developed within 24 hours of age requiring phototherapy from day 3. On day 5 there was a sudden fall in $\mathrm{Hb}$ from 139 to $95 \mathrm{~g} / \mathrm{l}$ and a rise in serum bilirubin concentration from 227 to $311 \mu \mathrm{mol} / \mathrm{l}$ despite phototherapy. His condition deteriorated rapidly, so that six hours later he was anaemic ( $\mathrm{Hb} 45 \mathrm{~g} / \mathrm{l}$, white cell count (WCC) $5.6 \times 10^{9} / \mathrm{l}$, and platelet count $325 \times 10^{9} / \mathrm{l}$ ) with hepatomegaly and poor perfusion. He suffered a profound apnoeic episode from which he did not recover despite full cardiopulmonary resuscitation. Blood film showed fragmented red blood cells but no Heinz bodies. Urinalysis was negative. Before the collapse he was well saturated (oxygen saturation 98\%) and not acidotic ( $\mathrm{pH} 7.38$ ). G6PD assay performed on the pre-transfusion blood showed reduced enzyme activity of $56.9 \mathrm{U} / 10^{12}$ red blood cells (normal $=260$ 650; Cobas Fara method using Sigma kit; Sigma Diagnostics). At postmortem examination, a small amount of blood was present in the subarachnoid space which was not sufficient to explain the anaemia. There was no evidence of bleeding from any other sites. Full infection screen taken at the time of the collapse-including cultures of blood, cerebrospinal fluid, urine, oropharyngeal secretions for bacteriology-and all cultures taken at the postmortem examination (including umbilical and central venous line catheter tips) was sterile.

Twin 2 was a boy weighing $990 \mathrm{~g}$ of blood group O positive with a negative DCT. He also required intubation, ventilation, and surfactant for respiratory distress syndrome. He was extubated on day 4, and TPN was given from days 3 to 8 . Cranial ultrasound scans were normal, and a full infection screen was negative. G6PD enzyme assay result showed reduced enzyme activity ( $33 \mathrm{U} / 10^{12}$ red blood cells; Cobas Fara method using Sigma kit). Within 24 hours of age he developed jaundice and was given phototherapy for 5 days (maximum serum bilirubin $286 \mu \mathrm{mol} / \mathrm{l}$ ). Hb remained stable until day 11 when there was a sudden fall to $78 \mathrm{~g} / \mathrm{l}$. Although the infant remained well, a decision was made to perform an exchange transfusion. Before the exchange, the blood counts were $\mathrm{Hb} 43 \mathrm{~g} / \mathrm{l}$, WCC $7.9 \times 10^{9} /$, platelet count $174 \times 10^{9} / \mathrm{l}$, with normal blood film morphology. Double volume exchange using whole blood (O negative) was uneventful. Blood cultures performed before and after the exchange were negative. In view of his brother's fate, it was felt that twin 2 was at a high risk of death from an acute episode of haemolysis. Therefore, his $\mathrm{Hb}$ was closely monitored. He was started on a regimen of regular blood transfusions to maintain a high proportion of his blood volume as transfused blood and thereby minimise G6PD deficient red blood cells. In spite of this, he required three further transfusions because of haemolysis (increased reticulocytosis of $7.5 \%$; absolute count $243 \times 10^{9} / 1\left(\right.$ normal $\left.\left.(2.0-100.0) \times 10^{9} / 1\right)\right)$ in the first 4 months of life. He has subsequently remained well and transfusion free, with no further episodes of haemolysis up to the age of 4 years. Further haematological investigations performed at 1 year of age confirmed G6PD deficiency

Abbreviations: DCT, direct Coombs test; G6PD, glucose-6-phosphate dehydrogenase; $\mathrm{Hb}$, haemoglobin concentration; TPN, total parenteral nutrition; WCC, white cell count 
in twin 2 and carrier status of the mother (level $=5.6 \mathrm{U} / \mathrm{g}$ $\mathrm{Hb}$ (normal 7.0-20.4; Cobas Fara method using Sigma kit), but absence of any other erythrocyte abnormality. This twin subsequently behaved like a G6PD deficient patient with no evidence of chronic haemolysis by 4 years of age.

Drugs administered to both twins were konakion (intramuscular), benzylpenicillin (intravenous), gentamicin (intravenous), cefotaxime (intravenous), vancomycin (intravenous), aminophylline (intravenous), and caffeine citrate (oral).

Case 3 was a term female infant (birth weight $3300 \mathrm{~g}$ ) of consanguineous Pakistani parents. Maternal blood group was A positive with no abnormal antibodies detected. Pregnancy was unremarkable. Postnatal examination was normal and she was discharged home the next day having received an oral dose of vitamin $\mathrm{K}_{1}$ (Konakion MM; l mg) and established on formula milk feeds. She received no other drugs. She was readmitted on day 6 with increasing jaundice for 48 hours. Clinical signs were negative except the presence of pronounced jaundice. Initial blood results were $\mathrm{Hb} 118 \mathrm{~g} / \mathrm{l}$, WCC $16.8 \times 10^{9} / \mathrm{l}$, platelet count $410 \times 10^{9} / \mathrm{l}$, packed cell volume 0.34 , red cell count $3.03 \times 10^{12} /$, blood group $\mathrm{O}$ positive, DCT negative, total serum bilirubin $468 \mu \mathrm{mol} / \mathrm{l}$, and direct serum bilirubin 0 . Total serum bilirubin fell gradually over the next 24 hours and the Hb remained stable at $112 \mathrm{~g} / \mathrm{l}$, on a regimen of oral and intravenous fluids and phototherapy. Forty eight hours after admission, the Hb suddenly dropped to $52 \mathrm{~g} / \mathrm{l}$, the packed cell volume was 0.14 , the red cell count $1.25 \times 10^{12} /$, WCC $20.1 \times 10^{9} /$, platelet count $495 \times 10^{9} / 1$, and the blood film showed red cell fragmentation, burr cells, nucleated red blood cells, and Howell-Jolly bodies, and total serum bilirubin increased to $408 \mu \mathrm{mol} / \mathrm{l}$. Heinz bodies were absent and urinalysis was normal. She had received no drugs, and an infection screen performed at the time, including blood and urine cultures, malarial screen, and surface swabs, was sterile. Renal function was normal and there was no evidence of disseminated intravascular coagulation or blood loss. A single volume exchange transfusion was performed. Subsequent course was uneventful and she was discharged home at 12 days of age with an $\mathrm{Hb}$ of $124 \mathrm{~g} / \mathrm{l}$ and serum bilirubin of $115 \mu \mathrm{mol} / \mathrm{l}$. Bloods results taken before the exchange transfusion confirmed the severe G6PD deficiency (G6PD activity was $0.2 \mathrm{U} / \mathrm{g} \mathrm{Hb}$ (normal 7.0-20.4; Cobas Fara method using Sigma kit). Haemoglobin electrophoresis showed no evidence of haemoglobinopathy, and pyruvate kinase activity was normal. She was reviewed at 2 months of age having remained well with a stable full blood count and normal blood film morphology.

\section{DISCUSSION}

G6PD is required for the generation of NADPH, which maintains glutathione in the reduced form, to counteract the day to day oxidant stresses on the erythrocyte. Although G6PD deficiency affects all cells, its primary effects are haematological because the erythrocyte has no alternative source of NADPH. It is inherited in an X linked fashion with, male hemizygotes and female homozygotes invariably more severely affected than female heterozygotes. ${ }^{1}$

Hyperbilirubinaemia resulting from G6PD deficiency is well documented in the newborn period $^{23}$; however, its pathogenesis is not completely understood. Although, deficiencies in the hepatic bilirubin conjugation and elimination process play a major part in the pathogenesis of hyperbilirubinaemia, ${ }^{12} 45$ haemolysis of G6PD deficient erythrocytes also has a role. ${ }^{7-9}$ The absence of frank anaemia in G6PD deficient infants with severe neonatal jaundice is often interpreted as indicating absence of increased rates of haemolysis. However, there is no doubt from reports of trigger factor induced acute haemolysis ${ }^{10}{ }^{11}$ and studies on haematological markers of haemolysis ${ }^{7-9}$ that haemolysis occurs at higher rates in neonates with G6PD deficiency than in G6PD normal neonates. Haemolysis in neonates with G6PD deficiency is usually reported to be secondary to trigger factors and often mild to moderate in relation to the degree of hyperbilirubinaemia, ${ }^{72}$ and not commonly associated with anaemia. Massive acute haemolysis in the newborn period, resulting in sudden anaemia, in the absence of trigger factor(s) in either the mother or the infant, is rare.

Although most newborn infants with G6PD deficiency will be free of haemolytic problems, a few are potentially at risk for development of severe hyperbilirubinaemia and anaemia. Certain G6PD mutation variants, seen in some racial groups, may increase the susceptibility to severe haemolysis, ${ }^{13-15}$ although this genetic analysis was not performed in our three cases. G6PD deficiency in a premature infant is especially handicapping. Normal premature infants have shortened erythrocyte survival, ${ }^{16}$ which, coupled with G6PD deficiency, makes the erythrocyte particularly vulnerable to oxidative injury.

Furthermore, factors other than oxidising drugs and infections may precipitate haemolysis in G6PD deficient newborns. Neonatal haemolysis in G6PD deficiency has been well documented with exposure to fava beans ${ }^{17}$ and with naphthalene in mothballs. ${ }^{18}$ In our three cases, thorough questioning revealed no history of fava bean ingestion by any of the mothers or exposure to mothballs in any of the babies. Furthermore, neither the infants nor their mothers had received any agents associated with haemolytic episodes in G6PD deficient subjects, except vitamin $\mathrm{K}^{19}$ It is impossible to state with certainty whether the doses of vitamin $\mathrm{K}$ received by these patients influenced the course of the haemolysis. This is unlikely, ${ }^{20}$ however, as the episodes of severe haemolysis did not occur until 5-11 days after the vitamin $\mathrm{K}$ dose. None of the three patients received supplementary vitamin $\mathrm{C}$, and none had evidence of Heinz bodies or haemoglobinuria, making this as cause of haemolysis extremely unlikely. ${ }^{21}$ In case 2 the persistent anaemia in the first 4 months of age was associated with increased reticulocytosis $(7.5 \%)$ and not due to erythropoietic shutdown which occurs in premature infants, although this may have contributed to the severity and acuteness of the anaemia as a consequence of haemolysis. As all three patients were healthy neonates, with no evidence of gastrointestinal disease or infection, haemolysis associated with $\mathrm{T}$ cell activation ${ }^{22-24}$ would have been highly unlikely, although this was not specifically tested. None of the infants were acidotic or hypoxaemic at the time of acute haemolysis. No other obvious factors that may have precipitated the episodes of haemolysis could be identified. The likelihood that such factors were present but not detected is very small, because the infants were observed in hospital and perinatal drug ingestion was known.

These three cases give support to the theory that massive haemolysis, although rare, does occur in neonates with G6PD deficiency, even in the absence of obvious precipitating factors. G6PD deficiency is no longer a condition limited to the boundaries of developing countries. Current ease of travel, migration of population groups, and intermarriage has allowed the penetration of the G6PD deficiency gene into populations and geographical areas far away from its places of origin and has resulted in cosmopolitan neonatal nurseries. It is in these populations where both the doctors and public are unfamiliar with the clinical manifestations and dangers of G6PD deficiency that catastrophic complications of G6PD deficiency are likely to occur.

\section{Authors' affiliations}

A S Dhillon, Department of Neonatology, Birmingham Women's Hospital, Birmingham B15 2TG, UK 
P J Darbyshire, M D Williams, Department of Haematology, Birmingham Children's Hospital, Birmingham B4 6NH

J G Bissenden, Department of Paediatrics, City Hospital, Birmingham B18 7QH

Correspondence to: Dr Dhillon, Neonatal Unit, Birmingham Women's Hospital, Edgbaston, Birmingham B15 2TG UK;

amritdhillon@hotmail.com

Accepted 29 November 2002

\section{REFERENCES}

1 Beutler E. G6PD deficiency. Blood 1994;84:3613-36.

2 Kaplan $M$, Hammerman C. Severe neonatal hyperbilirubinemia. A potential complication of glucose-6-phosphate dehydrogenase deficiency. Clin Perinatol 1998:25:575-90

3 Valaes T. Severe neonatal jaundice associated with glucose-6-phosphate dehydrogenase deficiency: Pathogenesis and global epidemiology. Acta Paediatr 1994;394(suppl): 58-76.

4 Kaplan M, Beutler E, Vreman HJ, et al. Neonatal hyperbilirubinemia in glucose-6-phosphate dehydrogenase-deficient heterozygotes. Pediatrics 1999;104:68-74

5 lolascon A, Faienza MF, Perrotta S, et al. Gilbert's syndrome and jaundice in glucose-6-phosphate dehydrogenase deficient neonates. Haematologica 1999:84:99-102.

6 Eshaghpour E, Oski FA, Williams M. The relationship of erythrocyte glucose6-phosphate dehydrogenase deficiency to hyperbilirubinaemia in Negro premature infants. J Pediatr 1967;70:595-601.

7 Valaes T, Karaklis A, Stravrakakis D, et al. Incidence and mechanism of neonatal jaundice related to glucose-6-phosphate deficiency. Pediatr Res 1969:3:448-58.

8 Kaplan M, Vreman HJ, Hammerman C, et al. Contribution of haemolysis to jaundice in Sephardic Jewish glucose-6-phosphate dehydrogenase deficient neonates. Br J Haematol 1996:93:822-7.

9 Necheles TF, Rai US, Valaes T. The role of hemolysis in neonatal hyperbilirubinaemia as reflected in carboxyhaemoglobin levels. Acta Paediatr Scand 1976;65:361-7.
10 Taj-Eldin S. Favism in breast-fed infants. Arch Dis Child 1971:46:121-3.

11 Zinkham WH. Peripheral blood and bilirubin values in normal full-term primaquine-sensitive negro infants: Effect of vitamin K. Pediatrics 1963;31:983-95.

12 Meloni T, Costa S, Cutillo S. Haptoglobin, hemopexin, hemoglobin and hematocrit in newborns with erythrocyte of glucose-6-phosphate dehydrogenase deficiency. Acta Haematol 1975;54:284-8.

13 Vulliamy TJ, Kaeda JS, Ait-Chafa D, et al. Clinical and haematological consequences of recurrent G6PD mutations and a single new mutation causing chronic nonspherocytic haemolytic anaemia. Br J Haematol 1998;101:670-5.

14 Vlachos A, Westwood B, Lipton JM, et al. G6PD Mount Sinai: a new severe hemolytic variant characterized by dual mutations at nucleotides $376 \mathrm{G}$ and $1159 T$ (N126D). Hum Mutat 1998; (suppl 1):S154-5.

15 Ainoon O, Joyce J, Boo NY, et al. Glucose-6-phosphate dehydrogenase (G6PD) variants in Malaysian Chinese. Hum Mut 1999;14:352.

16 Kaplan E, Hsu KS. Determination of erythrocyte survival in newborn infants by means of $\mathrm{Cr}^{51}$-labeled erythrocytes. Pediatrics 1961;27:354-61.

17 Mentzer WC Jr, Collier E. Hydrops fetalis associated with erythrocyte G-6-PD deficiency and maternal ingestion of fava beans and ascorbic acid. J Pediatr 1975;86:565-7.

18 Valaes T, Doxiadis SA, Fessas P. Acute hemolysis due to naphthalene inhalation. J Pediatr 1963;63:904-15.

19 Lucey JF, Dolan RG. Hyperbilirubinaemia of newborn infants associated with parenteral administration of a vitamin $\mathrm{K}$ analogue to the mothers. Pediatrics 1959;23:553-60.

20 Kaplan M, Waisman D, Mazor D, et al. Effect of vitamin K1 on glucose-6phosphate dehydrogenase deficient neonatal erythrocytes in vitro. Arch Dis Child Fetal Neonatal Ed 1998;79:F218-20.

21 Ballin A, Brown EJ, Koren G, et al. Vitamin C-induced erythrocyte damage in premature infants. J Pediatr 1988;113:114-20.

22 Squire R, Kiely E, Drake D, et al. Intravascular haemolysis in association with necrotising enterocolitis. J Pediatr Surg 1992;27:808-10.

23 Osborn DA, Lui K, Pussell P, et al. T and Tk antigen activation in necrotising enterocolitis: manifestations, severity of illness, and effectiveness of testing. Arch Dis Child Fetal Neonatal Ed 1999;80:F192-7.

24 Sethi S, Dhingra N, Madan N, et al. Erythrocyte T-activation: clinical importance and recognition by a simple routine technique. Ind J Path Microbiol 1994;37:109-11 